\title{
A Rare Cause of Hypopyon Anterior Uveitis: Relapsing Polychondritis
}

\author{
Nilüfer ZORLUTUNA KAYMAK ${ }^{1}$, , Murat OKLAR ${ }^{1}{ }^{\circledR}$, Burak TANYILDIZ1ํㅜ, \\ Mehmet Engin TEZCAN ${ }^{2} \mathbb{D}$, Şaban ȘİMŞEK ${ }^{1} \mathbb{D}$
}

${ }^{1}$ Department of Ophthalmology, Medical Health Sciences University, Kartal Dr. Lütfi Kirdar Training and Research Hospital, Istanbul, Turkey

${ }^{2}$ Department of Rheumatology, Medical Health Sciences University, Kartal Dr. Lütfi Kirdar Training And Research Hospital, Istanbul, Turkey

\section{ABSTRACT}

Relapsing polychondritis (RP) is a rare multisystemic disease. It affects cartilage and proteoglycan-rich structures. Ocular findings are the most frequent systemic involvement of the disease. The most common ocular manifestations are episcleritis and scleritis. During the course of the disease, uveitis may also be seen. However, as far as we know, nongranulomatous anterior uveitis with hypopyon is an uncommon ocular finding. In this article, we report a 27-year-old male patient who presented with hypopyon anterior uveitis as a revealing manifestation of RP.

Keywords: Hypopyon uveitis, ocular manifestations, relapsing polychondritis.

Relapsing polychondritis (RP) is a rare, autoimmune, multisystemic disease with unknown etiology. It affects all types of cartilages and proteoglycan-rich structures. ${ }^{1}$ The prominent manifestations of the disease are recurrent inflammatory involvements of eye, otorhinolaryngeal and bronchial cartilage, cardiovascular system, musculoskeletal structures, kidney, central nervous system and skin. ${ }^{2}$ The most frequent presenting feature of the disease is auricular chondritis. ${ }^{1}$

Ocular involvement may be seen in 37 to $65 \%$ of $\mathrm{RP}$ patients. ${ }^{1}$ Moreover, in one third of $\mathrm{RP}$ patients, eye involvement may be the presenting finding of the disease. Although all ocular structures can be affected, the most frequent ocular involvements are scleritis and episcleritis. ${ }^{3,4}$ Nongranulomatous anterior uveitis is also a common feature in RP; however, uveitis with hypopyon is a rare finding. ${ }^{5-8}$ In this article, we presented a male patient with hypopyon uveitis as the first manifestation of RP.

\section{CASE REPORT}

A 27-year-old male patient referred to the hospital with symptoms of unilateral pain, redness, photophobia and blurred vision in his right eye. His symptoms had started three days before. In his first examination, visual acuity was 0.6 in the right eye and 0.3 in the left eye. Anisometropic amblyopia since his childhood was considered as the reason for decreased visual acuity in his left eye. The slit lamp examination of the right eye revealed conjunctival congestion, nongranulomatous keratic precipitates on the inferior half of the cornea, $3+$ cells in the anterior chamber with a 1-mm hypopyon and pigments on the lens surface (Figure 1). There

Received: January 14, 2019 Accepted: May 08, 2019 Published online: November 06, 2019

Correspondence: Nilüfer Zorlutuna Kaymak, MD. SBÜ Kartal Dr. Lütfi Kırdar Eğitim ve Araştırma Hastanesi Göz Hastalıkları Kliniği, 34890 Kartal, İstanbul, Turkey. Tel: +90 216 - 4413900 e-mail:n_zorlutuna@yahoo.com 


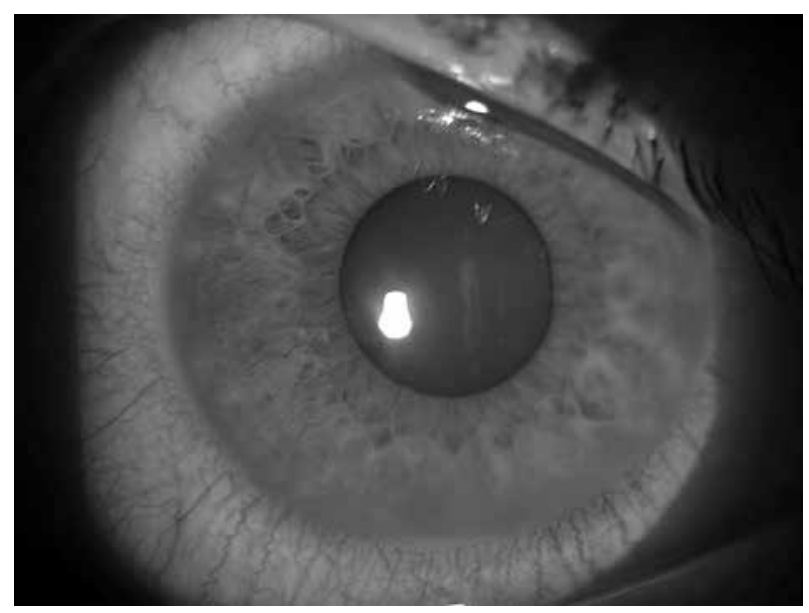

Figure 1. Anterior segment photography of inflamed right eye.

were no pathologic findings in the slit lamp examination of the left eye. In the fundus examination, optic disc hyperemia was observed in his both eyes. Also, intraocular pressures of both eyes were within the normal ranges. Lastly, fundus fluorescein angiography showed disc hyperfluorescence in both eyes. We also observed moderate edema and tenderness in his left ear (Figure 2). All other systemic examinations were normal. He did not report any previous ocular symptoms except anisometropic amblyopia in his left eye. Furthermore, he had a complaint of night sweating, vertigo and $8 \mathrm{~kg}$ weight loss in the last month. He had no significant family history. Then, we ordered laboratory exams. Herein, his acute phase reactant levels were high. Erythrocyte sedimentation rate was $56 \mathrm{~mm} /$ hour and C-reactive protein level was $90.8 \mathrm{mg} / \mathrm{L}$. Full blood count, renal and liver function tests were normal. Thereafter, we evaluated the patient for other systemic diseases with antinuclear antibodies, rheumatoid factor, human leukocyte antigen-B27 (HLA-B27), antineutrophil antibody, anti-extractable nuclear antigens, pathergy, syphilis tests, hepatitis markers and human immunodeficiency virus serology. All results were negative. Tuberculin skin test was $3 \mathrm{~mm}$. His treatment was started with hourly topical $1 \%$ prednisolone acetate and 1\% tropicamide three times daily. One day after his admission, he complained of new onset of pain in his left ear and swelling in postauricular and preauricular lymph nodes. On follow-up examinations, inflammation in his right eye completely resolved within seven

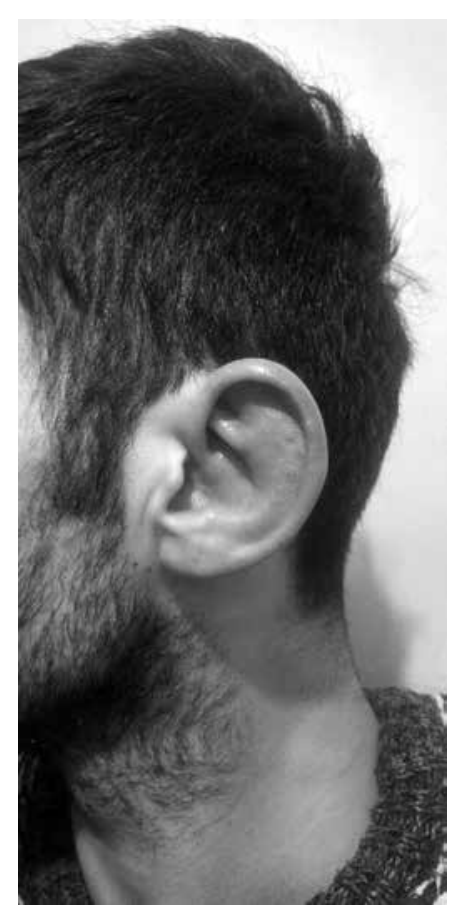

Figure 2. Auricular chondritis in the left ear of the patient.

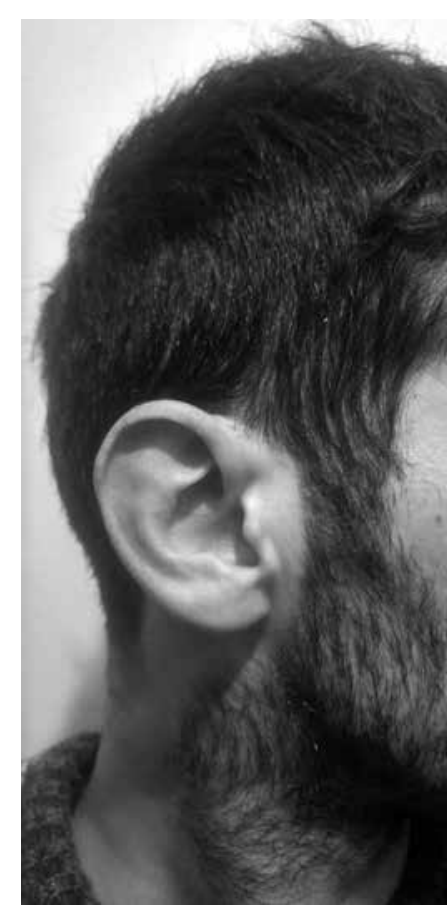

Figure 3. Auricular chondritis in the right ear of the patient. 


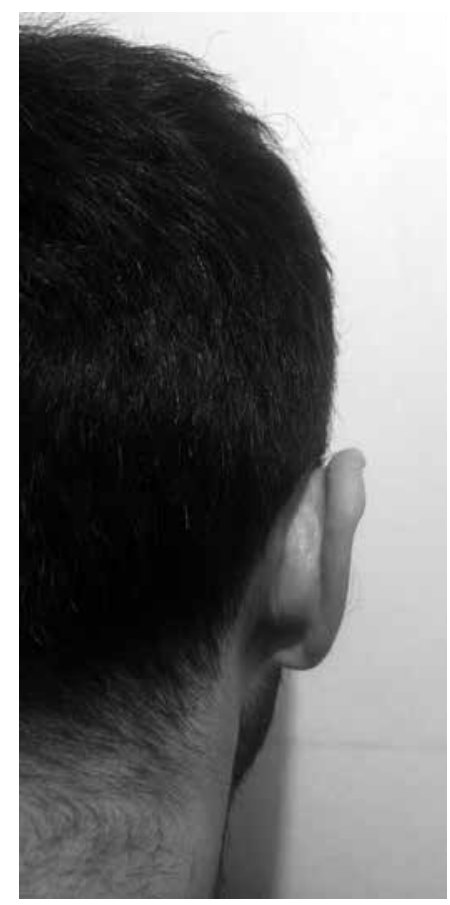

Figure 4. Right auricular chondritis is more prominent from the backside.

days. However, chondritis in his right ear became more significant (Figures 3, 4). According to his findings, he was diagnosed as RP. Then, we started methylprednisolone $32 \mathrm{mg} /$ day and methotrexate $15 \mathrm{mg} /$ week. With these treatments, chondritis in both ears were completely resolved within 10 days. During the course of treatment, he had no further ocular or systemic findings. A written informed consent was obtained from the patient.

\section{DISCUSSION}

Ocular manifestations of RP may be seen in 37 to $65 \%$ of patients. ${ }^{1}$ Ocular symptoms can be the presenting features of the disease in $32 \%$ of patients. ${ }^{2}$ Uveitis is seen in up to $30 \%$ of patients with RP. ${ }^{3}$ Most frequent type of uveitis is nongranulomatous anterior uveitis with concomitant scleritis. However, hypopyon uveitis is an uncommon ocular involvement. ${ }^{9,10}$ As far as we know, only four reports (five cases) have been published in the literature. ${ }^{5-8}$ Genevois et al. ${ }^{5}$ and Lim and $\mathrm{Han}^{6}$ published two RP cases with hypopyon uveitis. These patients had no scleritis similiar to our patient. Furthermore, Anderson et al. $^{7}$ reported two patients, one of whom was a 70-year-old male patient who developed hypopyon uveitis with scleritis and polyarthritis as the presenting symptom of RP. The other patient was a 42-year-old female patient. This patient also developed bilateral hypopyon uveitis without scleritis 10 years after the diagnosis of RP. ${ }^{7}$ Lastly, Ben Salah et al. ${ }^{8}$ reported a patient with recurrent anterior uveitis with hypopyon, starting 10 years after the diagnosis of RP. ${ }^{8}$

Hypopyon uveitis is most frequently seen in the presence of Behçet disease (BD). The distinctive description of the ocular involvement in $\mathrm{BD}$ is iridocyclitis with a hypopyon. However, nongranulomatous acute iridocyclitis without hypopyon is the most common form of the anterior segment inflammation in BD. Herein, posterior segment inflammation often accompanies anterior chamber involvement. The classic description of ocular involvement in $\mathrm{BD}$ is iridocyclitis with a hypopyon. ${ }^{11}$ The Systemic Immunosuppressive Therapy for Eye Diseases Cohort Study retrospectively analyzed the prevalence and incidence of hypopyon in 4,911 patients with uveitis. ${ }^{12}$ It is important to note that $\mathrm{BD}$ conferred a five-fold increased risk of hypopyon, whereas HLA-B27 positivity or spondyloarthropathy was associated with a two-fold increased risk. This article suggests that the presence of hypopyon in a patient with uveitis implies a greater likelihood of BD. Ankylosing spondylitis and other HLA-B27-associated autoimmune diseases such as Reiter's syndrome, psoriatic arthritis and inflammatory bowel disease are associated with hypopyon uveitis complicated by acute anterior uveitis (AAU). ${ }^{13}$ Power et al. ${ }^{14}$ and D'Alessandro et al. ${ }^{15}$ found that the majority of patients with anterior uveitis who presented with hypopyon had a positive HLA-B27 antigen. They reported the prevalence of hypopyon in their series as $14.1 \%$ and $14.5 \%$, respectively. Tuncer et al. ${ }^{16}$ also reported that $18 \%$ of their HLA-B27 positive AAU patients had hypopyon formation. Our patient was negative for HLA-B27 antigen and did not meet the criteria for BD.

Relapsing polychondritis may coexist with other systemic diseases such as systemic vasculitis, autoimmune or malignant disorders. McAdam et al. ${ }^{17}$ showed that $25-35 \%$ of their RP patients had concomitant systemic diseases. Therefore, in patients with RP, it is important to rule out 
other systemic vasculitis, autoimmune diseases or malignancies. According to our patient's medical past history, he had night sweating, vertigo and weight loss; however, there was no coexisting pathology in his systemic examination.

In conclusion, hypopyon uveitis may be the first manifestation of RP. As demonstrated in this case, all patients with uveitis should be evaluated for systemic inflammatory diseases for early diagnosis and appropriate treatment.

\section{Declaration of conflicting interests}

The authors declared no conflicts of interest with respect to the authorship and/or publication of this article.

\section{Funding}

The authors received no financial support for the research and/or authorship of this article.

\section{REFERENCES}

1. Lekpa FK, Chevalier X. Refractory relapsing polychondritis: challenges and solutions. Open Access Rheumatol 2018;10:1-11.

2. Letko E, Zafirakis P, Baltatzis S, Voudouri A, LivirRallatos C, Foster CS. Relapsing polychondritis: a clinical review. Semin Arthritis Rheum 2002;31:384-95.

3. Isaak BL, Liesegang TJ, Michet CJ Jr. Ocular and systemic findings in relapsing polychondritis. Ophthalmology 1986;93:681-9.

4. Zeuner M, Straub RH, Rauh G, Albert ED, Schölmerich J, Lang B. Relapsing polychondritis: clinical and immunogenetic analysis of 62 patients. J Rheumatol 1997;24:96-101.

5. Genevois O, Calenda E, Nasser Z, Benzerroug M, Gardea E, Muraine M. Hypopyon uveitis (without scleritis) a manifestation symptom of relapsing polychondritis. Ann Ophthalmol (Skokie) 2009;41:208-11.

6. Lim TH, Han JI. A case of hypopyon uveitis associated with relapsing polychondritis. J Korean Ophthalmol Soc 2009;50:486-90.

7. Anderson NG, Garcia-Valenzuela E, Martin DF. Hypopyon uveitis and relapsing polychondritis: a report of 2 patients and review of autoimmune hypopyon uveitis. Ophthalmology 2004;111:1251-4.

8. Ben Salah R, Frikha F, Hentati Y, Kallel S, Ghorbel A, Mnif Z, et al. Recurrent anterior uveitis with hypopyon revealing relapsing polychondritis. Intern Med 2012;51:3173-6.

9. Matas BR. Iridocyclitis associated with relapsing polychondritis. Arch Ophthalmol 1970;84:474-6.

10. Brink $H$, Rademakers J, Verbeek A, van Ede A, Tilanus S. Ocular manifestations of relapsing polychondritis. Three case histories. Doc Ophthalmol 1994;87:159-66.

11. Tugal-Tutkun I, Gupta V, Cunningham ET. Differential diagnosis of behçet uveitis. Ocul Immunol Inflamm 2013;21:337-50.

12. Zaidi AA, Ying GS, Daniel E, Gangaputra S, Rosenbaum JT, Suhler EB,et al. Hypopyon in patients with uveitis. Ophthalmology 2010;117:366-72.

13. Maza MS. Seronegative spondyloarthropaties. In: Foster SC, Vitale TA, editors. Diagnosis \& Treatment of Uveitis. 2nd ed. New Delhi: Jaypee-Highlights; 2013. p. 793-813.

14. Power WJ, Rodriguez A, Pedroza-Seres M, Foster CS. Outcomes in anterior uveitis associated with the HLAB27 haplotype. Ophthalmology 1998;105:1646-51.

15. D'Alessandro LP, Forster DJ, Rao NA. Anterior uveitis and hypopyon. Am J Ophthalmol 1991;112:317-21.

16. Tuncer S, Adam YS, Urgancioglu M, Tugal-Tutkun I. Clinical features and outcomes of HLA-b27-positive and HLA-B27-negative acute anterior uveitis in a Turkish patient population. Ocul Immunol Inflamm 2005;13:367-73.

17. McAdam LP, O'Hanlan MA, Bluestone R, Pearson CM. Relapsing polychondritis: prospective study of 23 patients and a review of the literature. Medicine (Baltimore) 1976;55:193-215. 